\title{
PAH and POP Presence in Plastic Waste and Recyclates: State of the Art
}

\author{
Juan A. Conesa ${ }^{1,2, * \mathbb{D}}$, Samuel S. Nuñez ${ }^{2} \mathbb{D}$, Núria Ortuño ${ }^{2} \mathbb{D}$ and Julia Moltó ${ }^{1,2}$ \\ 1 Department of Chemical Engineering, University of Alicante, P.O. Box 99, E-03080 Alicante, Spain; \\ julia.molto@ua.es \\ 2 Institute of Chemical Process Engineering, University of Alicante, P.O. Box 99, E-03080 Alicante, Spain; \\ samuel.nr@ua.es (S.S.N.); nuria.ortuno@ua.es (N.O.) \\ * Correspondence: ja.conesa@ua.es; Tel.: +34-965-903-400
}

Citation: Conesa, J.A.; Nuñez, S.S.; Ortuño, N.; Moltó, J. PAH and POP Presence in Plastic Waste and Recyclates: State of the Art. Energies 2021, 14, 3451. https://doi.org/ $10.3390 /$ en14123451

Academic Editor: Frede Blaabjerg

Received: 27 May 2021

Accepted: 8 June 2021

Published: 10 June 2021

Publisher's Note: MDPI stays neutral with regard to jurisdictional claims in published maps and institutional affiliations.

Copyright: (c) 2021 by the authors. Licensee MDPI, Basel, Switzerland. This article is an open access article distributed under the terms and conditions of the Creative Commons Attribution (CC BY) license (https:// creativecommons.org/licenses/by/ $4.0 /)$.

\begin{abstract}
The presence of different pollutants in recycled plastics is reviewed in this article. The desirable circular economy of plastics should be linked to the availability of clean recycled plastics with a non-significant and small to nil amount of substances of concern. Different researchers found polycyclic aromatic hydrocarbons (PAHs) and Persistent Organic Pollutants (POPs), such as brominated flame retardants (BFRs), pesticides, dioxins and furans (PCDD/Fs and PBDD/Fs) in plastic recyclates. This represents an added difficulty to the effective recycling process of plastics that reduces the demand for energy and materials, in addition to posing a great environmental danger since they represent a vector of accumulation of the contaminants that will finally appear in the most unexpected products. Life Cycle Analysis of the plastic wastes recycling process indicates a great saving of energy, water and $\mathrm{CO}_{2}$ emissions.
\end{abstract}

Keywords: plastic waste; dioxins; PCDD/Fs; BFRs; pesticides; legacy compounds; recyclates

\section{Introduction}

Plastics are increasingly used in our society and are a key point in the economy of sectors as diverse as packaging, transportation, construction, healthcare and electronics. Plastics pose a huge economic and social impact, thanks to their combination of low cost, versatility, durability and high strength-to-weight ratio [1]. The significant growth in plastic production in the last 50 years is a reflection of its great success; annual global plastic production has increased from 2 to 380 million tonnes since 1950, reaching 368 million tonnes in 2019 [2]. Plastic production is expected to double in 15 years and almost quadruple in 30 years [2]. Moreover, the global consumption of plastics has increased more than 20 times over the last half century, and it is estimated to double again by 2034 if action is not taken [3]. High production rates and a lack of consumer awareness have led to a large generation of plastic waste.

Traditionally, the dominant practice of business in production industries has been based on a Linear Economy model: using raw materials to produce a product and indirectly a waste that needs to be further disposed. With a growing world population, the amount of raw material requirements has increased exponentially, causing a significant negative impact on the social and natural environment. In response, the only long-term sustainable alternative is a more efficient circular economy, where resources are handled more competently.

The Circular Economy model aims to create value from waste by recovering and reusing resources. In all areas, waste is generated both in production (post-industrial waste) and use (post-consumer waste). Recycling can close the loop of a circular economy by re-introducing into the economy high-quality plastic recyclates incorporated into new products; this will significantly reduce the consumption of raw materials, saving both energy and $\mathrm{CO}_{2}$ emissions [4]. Recyclers operate at the end and at the beginning of the 
value chain, by recovering materials from End of Life (EoL) products and reintroducing them at the beginning of the process value chain [4].

In 2015, the European Commission adopted a European Union (EU) Action Plan for a circular economy [5]. In this plan, the EU identifies plastics as a priority and commits to launching a strategy that regulates the challenges posed by plastics and takes into account their entire life cycle.

To this regard, the European Commission formulated their vision on a more integrated system in 'A European Strategy for Plastics in a Circular Economy', published in 2018 [6]. In it, the EU set different objectives in order to monitor all aspects of the life cycle of plastics. Some of the targets put the focus on plastic packaging, as the packaging industry is the largest plastics market in the EU. In fact, of total plastic waste, packaging represents more than $60 \%$ [7]. To counter this, the European Commission declared that by 2030, all plastic packaging marketed in the EU must be reusable or cost-effectively recyclable. As of today, the recycling rate for plastic packaging is only $42 \%$ [2], which places the target quite far away.

\section{Plastic Waste Management}

In the European Union, the Waste Framework Directive 2008/98/EC7, recently revised by Directive (EU) 2018/852 [8], established a waste hierarchy that shall apply as a priority order in waste prevention, management legislation and policy. It aims to establish a trajectory to eliminate landfill disposal and reduce waste through re-using and recycling.

The terminology for plastic recycling has been standardized by the International Organization for Standardization (ISO) and the American Society for Testing and Materials (ASTM). The recycling routes have been classified into four categories defined as follows $[9,10]$ (see Figure 1):

- Primary recycling, which consists of the reintroduction of pre-consumer waste (chopped plastics, edges and pieces of industrial plastic or a single polymer) in the extrusion cycle in order to produce products of the same material (closed-loop recycling or upcycling). Reusing plastics through primary recycling is the best way to work in a circular economy.

- Secondary recycling or mechanical recycling, which includes operations that seek to recover solid plastic waste through mechanical processes. In this way, the new recycled material can be converted into new plastic products, different from the original ones, substituting virgin polymers or a portion of virgin polymers (downcycling). Reusing plastics through primary or secondary recycling enhances resource efficiency and is part of a circular economy approach. The successful recycling of separated plastics counts on different available technologies, but the effective recycling of mixed plastics waste is the next major challenge for the plastics recycling sector [11].

- Tertiary recycling, raw material recycling, or chemical recycling are the terms used for processes that obtain smaller molecules from polymer chains. These small molecules can be used as feedstock for the production of fuels, new polymers, or other chemicals. The following two main groups of methods can be distinguished: solvolysis, i.e., the dissolution/reprecipitation of polymers [12], and pyrolysis, i.e., decomposition into low molecular weight compounds by thermal cracking.

- Quaternary recycling, or energy recovery, which consists of the production of electricity and/or heat from the sensible heat provided by the combustion gases obtained by incinerating plastic waste.

In 2018, more than 60 million tonnes of plastic material were produced in Europe (EU-28 plus Norway and Switzerland), of which 29.1 million tonnes of plastic waste were collected in order to be treated [2]. Despite Europe being one of the most advanced regions regarding plastics collection and recycling, the recycling rate is still at $32.5 \%$, while energy recovery represents $42.63 \%$ and $24.9 \%$ is sent to landfill [2]. 


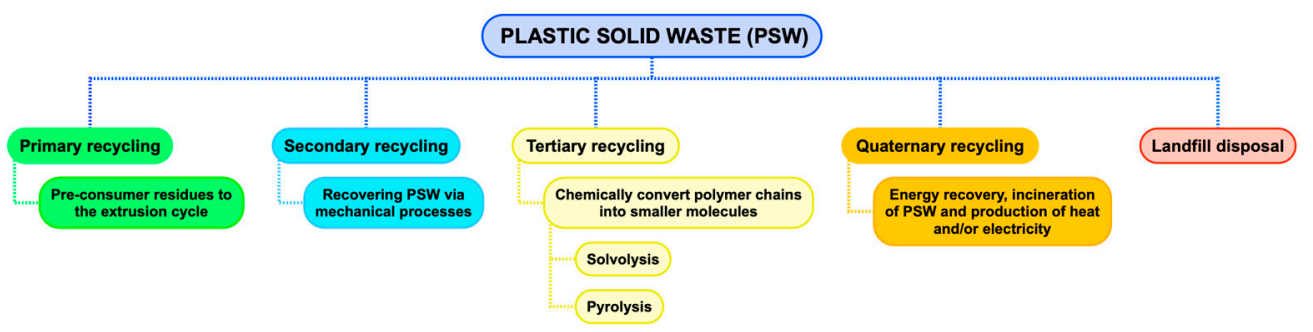

Figure 1. Plastic Solid Waste (PSW) management.

It is a well-known reality that a good management of any type of waste, including plastic solid waste (PSW), requires an appropriate combination of different technologies $[13,14]$.

The least-preferred management method for PSW is landfilling, but, unfortunately, worldwide most of it ends up in dumps (40\%), which contributes to the contamination of rivers and land with many pollutants [15]. Particularly important is the presence of POPs, which, by their nature, are bioaccumulated and highly dangerous. Among them, BFRs are the most studied.

The incineration of PSW, particularly when no optimal conditions are used, can produce different amounts of PAHs and POPs, including PCDD/Fs, BFRs, polybrominated dioxins and furans (PBDD/Fs) and polychlorinated biphenyls (PCBs) [16]. The formation of such pollutants in combustion chambers has been traditionally related to the presence of halogenated wastes, although the conditions of the furnaces are generally enough to destroy all of the entering compounds [17]. In this way, emission is more related to the presence of zones at temperatures between 200 and $400{ }^{\circ} \mathrm{C}$, where a catalytic synthesis of these compounds takes place $[18,19]$. Among the precursors of this synthesis are some BFRs that can promote the formation of highly toxic polybrominated dibenzo- $p$-dioxins and dibenzofurans [20]. The formation of PBDD/Fs has particularly been observed during the thermal treatment of plastics containing flame retardants associated with $\mathrm{SbO}_{3}$ [21], a synergist commonly used with polybrominated diphenyl ethers (PBDEs). Other thermal decomposition methods (pyrolysis, gasification and incineration in cement kilns) can also generate further POPs under different conditions.

\subsection{Energy and Environmental Savings}

Recycling undoubtedly implies considerable savings in both energy and natural resources. Although recycling uses an amount of energy, for sorting, transport, treatment, etc., in general much more is saved than is consumed. To make a new product, it is necessary to start the production process from scratch, which entails extra energy consumption. If that product is recycled, certain steps in the manufacturing process are skipped and that energy is saved. Furthermore, it is clear that a decrease in the use of virgin material and an increase in the reuse of PSW will contribute to the sustainability of the global warming situation.

Data available in the literature [11] show that the production, for example, of 1 tonne of polystyrene (PS) consumes $82.7 \mathrm{GJ}$ of energy, and that this amount is decreased to a maximum of $55 \mathrm{GJ}$ (min. $8 \mathrm{GJ}$ ) when recycled plastics are used. The same is true for other life cycle indicators such as $\mathrm{CO}_{2}$ emissions (decreasing from 3.4 to $1.4 \mathrm{t} /$ tonne) and water usage (from 140 to $3.5 \mathrm{~kL} /$ tonne). In this way, and according to the Waste Reduction Model of EPA [22], 1 tonne of recycled plastic saves $20 \mathrm{GJ}$ of energy and $23 \mathrm{~m}^{3}$ of landfill space.

A decrease in the use of virgin plastics and the reuse of PSW will help slow down the progress of climate change [23]. The incineration of PSW could also be considered as a recycling technique since PSW is used as a fuel and, being a by-product of oil, it has some calorific value, which in turn leads to the sustainability of natural resources. 


\subsection{Challenges in Plastic Recycling}

In the EU, the recycling of plastics in any of the aforementioned routes is very low, especially when compared to other materials such as paper, glass or metals. The recycling potential for plastic waste remains largely untapped [6]. The problem lies not only in the amount of plastic recycled, but also in the quality of the recycling and the resulting secondary plastic.

To make them fit our needs, plastic products contain a broad range of additives. These substances can, for example, be fillers, plasticizers, flame retardants, pigments, stabilizers, lubricants, foaming agents and antistatic agents that are used to improve the properties of the plastics and reduce costs, and are also known as Intentionally Added Substances (IASs) [24]. Other contaminants may also be unintentionally present, including catalyst residues, impurities and compounds produced from side reactions. These molecules that have not been consciously added are called Non-Intentionally Added Substances (NIASs) [25]. Some of the substances added to the plastics, be it intentionally or unintentionally, pose a risk to the environment and to human health due to their hazardous and/or toxic properties.

For a better recycling process of PSW, the presence of hazardous chemicals in plastics should be taken into account. In general, recyclers struggle to guarantee the exact content of secondary material, which limits recycling. In addition, it is necessary to develop methods to reduce the amount of these compounds in recycled plastics, in order to improve the applications of upcycling plastics, and prevent the health and environmental risks derived from the presence of hazardous substances in goods containing recycled materials. Different authors point out the necessity of establishing limit values on the content of these pollutants in the plastics that are going to be recycled, in order to avoid the contamination of consumer products [26]. A condition for the setting of these threshold values is the detailed knowledge of the presence of pollutants in waste, products and recyclates [27].

\section{Substances of Concern in Recycled Plastics: A Focus on PAHs and POPs}

Different authors $[25,28]$ have shown the importance of bearing in mind the presence of different substances in recyclates. Particularly alarming are those considered to be carcinogenic, such as many PAHs and POPs.

PAHs are a group of organic compounds made up of simple aromatic rings that have joined together and do not contain heteroatoms or carry any substituents. All PAHs are lipophilic in nature (i.e., they accumulate in the fatty tissue, which makes them very dangerous), solid at room temperature and formed as a result of incomplete combustion in both natural and anthropogenic processes. PAHs are found in oil, coal and tar deposits and also as products of the use of fuels (either fossils or biomass). As pollutants, they have raised concern because some of them have been identified as carcinogens, mutagens and teratogens. Different organizations have assessed their toxic properties and have classified PAHs into different groups. In Figure 2, we can find the most important PAHs and whether they are considered a priority by the following three different organizations: the EU Scientific Committee for Food (SCF), the European Union (EU) and the US Environmental Protection Agency (EPA) [29].

For their part, POPs are different groups of compounds that present a particular combination of physical and chemical properties that allow them to remain intact for years once they have been released into the environment. By their nature, POPs accumulate in the fatty tissue of living organisms, which is why they are found in higher concentrations at the highest levels of the food chain, while also being toxic to both humans and wildlife. 


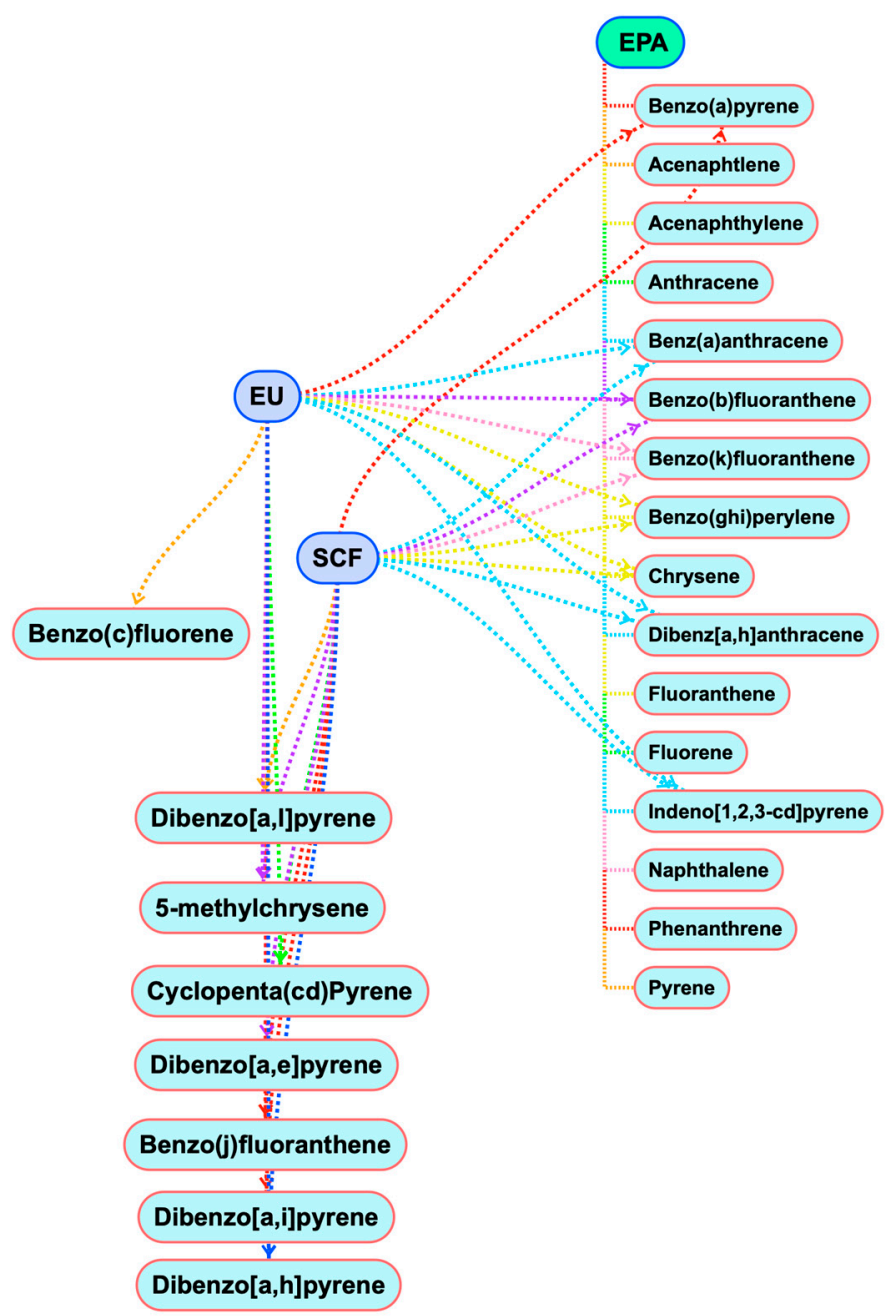

Figure 2. PAHs considered to be a priority by the EU Scientific Committee for Food (SCF), the European Union (EU) and the US Environmental Protection Agency (EPA).

Usually, POPs are divided into the following two groups (see Figure 3): 'legacy' POPs, i.e., substances with the particular properties of POPs that have been long-recognized as harmful and are controlled under international regulation since at least 2003, and 'emerging' or 'new' POPs that are being considered for banning purposes nowadays [30].

Under 'legacy' POPs, the following two different sets are included: different pesticides and dioxin-like compounds, including in this last group the dioxins (PCDDs), furans (PCDFs) and biphenyls (PCBs). On the other hand, the compounds included as 'new' POPs consist of a group of four brominated compounds that are used as flame retardants (BFRs), and other substances that are pollutants by themselves or that can give rise to very dangerous pollutants. 


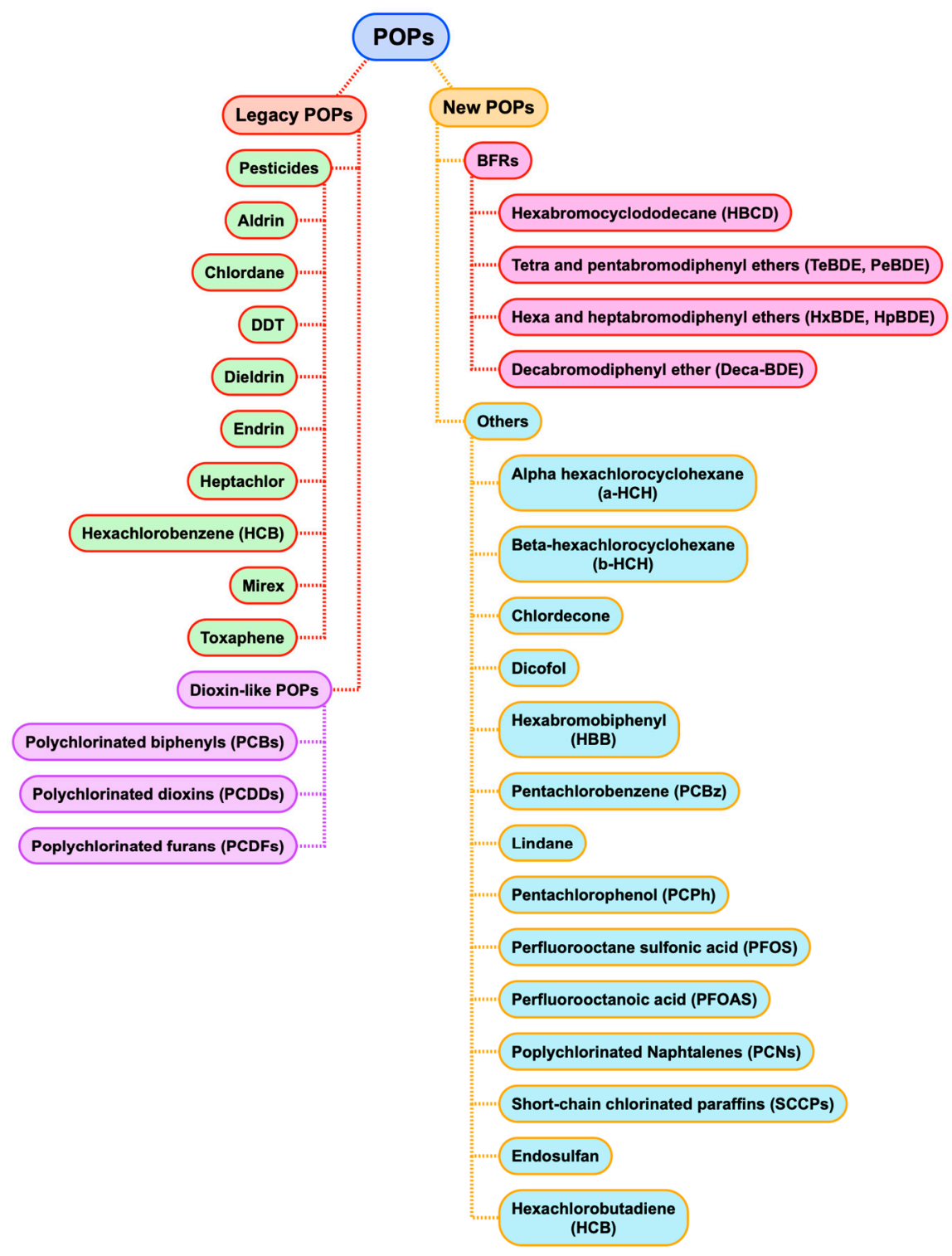

Figure 3. Persistent Organic Pollutants (POPs) considered in the Stockholm Convention.

\section{Techniques for the Isolation of PAHs and POPs from Plastic Samples}

Different techniques are used for the isolation and instrumental analysis of the considered contaminants. Commonly, an extraction with an appropriate organic solvent and a mild cleanup are performed.

The most widely used solvents to extract organic compounds are dichloromethane (DCM), isooctane, $\mathrm{n}$-hexane, toluene, acetone, pentane/DCM $(1: 1, v / v)$ and toluene/acetone $(1: 1, v / v)$. The extraction is usually aided by an ultrasonic bath in order to accelerate the process.

An extraction solvent's selection is mostly based on a comparison of the recovery results, which is time-consuming. A good approximation for the optimum selection of the appropriate solvent is performed by studying the values of the solubility parameter, ' $\delta$ ' [31].

A calculation of the parameter is performed by calculating the square root of gasification energy per unit volume of matter [32,33], in such a way that can be calculated for the different species [31,32]. This parameter is then calculated for both the solvents and the polymers, and the optimum situation is that where the same value of ' $\delta$ ' for a solvent and a polymer is achieved. This approximation is based on the fact that the enthalpy of mixing should be negative or close to zero to obtain a good mixing, and this is achieved when the 
solubility parameters are similar for a polymer and a solvent. This parameter has been used to study the presence of PBDEs, among others, in the surface of microplastics [31].

Figure 4 shows a scheme of the values of the solubility parameter for many different solvents generally used in the extraction of pollutants, and also the values of ' $\delta$ ' for different polymers [34]. In the diagram we can check that, for example, solvents such as methanol or ethanol are the best to solubilize Nylon, but n-hexane or ethyl acetate are more appropriate for LDPE. Many more values of the solubility parameter can be found in the literature, including for biopolymers [35].

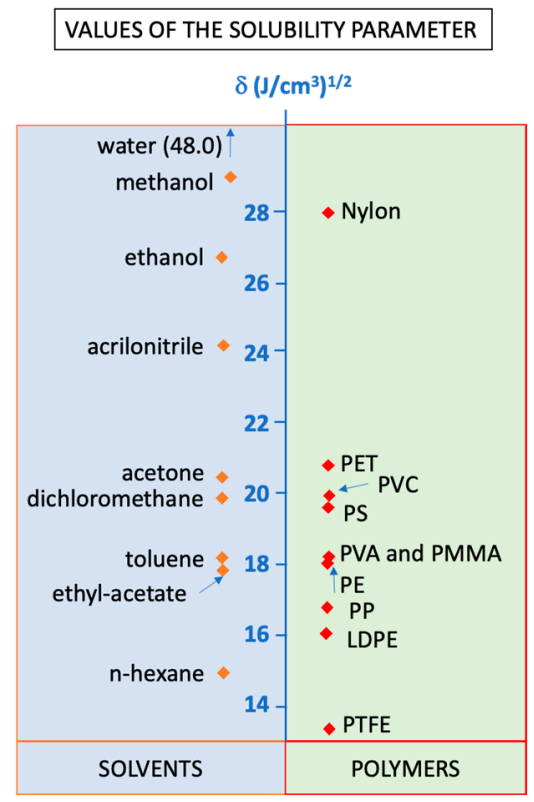

Figure 4. Diagram showing the values of the solubility parameter, $\delta\left[\left(J / \mathrm{cm}^{2}\right)^{1 / 2}\right]$, for different solvents and polymers.

Once the appropriate solvent has been selected, an extraction procedure should be defined. Li et al. [36] dissolved $2 \mathrm{~g}$ of PS in $10 \mathrm{~mL}$ of a mixture of acetone:DCM at a ratio of 1:1 $(v / v)$, using an ultrasonic bath for $30 \mathrm{~min}$. The liquid was centrifuged for eliminating the precipitated polymer. Singla et al. [31] compared the extraction recoveries of 12 PBDEs from microplastics using different solvents (acetonitrile, methanol, acetone, ethyl acetate, toluene and n-hexane). After $48 \mathrm{~h}$, the organic phase ( $2 \mathrm{~mL}$ of the corresponding solvent) was evaporated to dryness and reconstituted with hexane prior to analysis using GC-ECD. Nerin et al. [37] simply extracted pesticides from ethylene-vinyl acetate (EVA) and low density polyethylene (LDPE) using an ultrasonic bath and DCM. Pivnenko et al. [38] used $20 \mathrm{~mL}$ of n-hexane:isopropanol to extract $1 \mathrm{~g}$ of a plastic sample (acrylonitrile butadiene styrene (ABS), PS, polyethylene (PE)...). In this case, the authors used microwave heating at $100{ }^{\circ} \mathrm{C}$ for $60 \mathrm{~min}$ and centrifuged for $5 \mathrm{~min}$ at $2500 \mathrm{rpm}$. Rani et al. [39] also used DCM for dissolving PS, but no heat nor ultrasound was necessary to obtain a good recovery. Leon et al. [40] extracted both PAHs and pesticides (group of POPs) from marine plastic litter with methanol using an ultrasonic bath. Fisner et al. [41] used a 1:1 mixture of nhexane:DCM to extract PAHs. Iñiguez et al. [42] extracted PAHs and PCDD/Fs from plastic marine litter using a mixture of DCM:acetone and accelerated solvent extraction (ASE). Bouhroum et al. [43] achieved the extraction of PAHs and PCBs from different polymers (around $0.1 \mathrm{~g}$ ) with a 10-milliliter portion of a mixture of DCM:heptane at a ratio of 1:1 $(v / v)$, maintaining the contact for $24 \mathrm{~h}$. Finally, Horodytska et al. [25] introduced $1 \mathrm{~g}$ of grounded plastic into a 20-milliliter vial with $10 \mathrm{~mL}$ of DCM and stirred for $24 \mathrm{~h}$. After that, the solvent was decanted from the sample and stored for $12 \mathrm{~h}$ at $4{ }^{\circ} \mathrm{C}$ to separate the remaining solids. The extracts were then pre-filtered through glass wool and concentrated under a stream of nitrogen up to $1.5 \mathrm{~mL}$. 
A cleanup stage is sometimes required. Li et al. [36] used a C10 solid phase extraction (SPE) column for eluting PAHs with $5 \mathrm{~mL}$ of n-hexane:DCM at a ratio of 4:1 $(v / v)$. Other authors [41,44] used an alumina and/or silica column for isolating PAHs or POPs. A Florisil column can also be used for that purpose, according to DiGangi et al. [45].

\section{Presence of Contaminants in Recycled Plastics}

\subsection{PAHs}

Vapenka et al. [46] measured the concentration of different PAHs in materials used for food packaging, showing the presence of aromatic hydrocarbons in more than $50 \%$ of the tested materials. Values as high as $1212 \mathrm{mg} / \mathrm{kg}$ of fluorene were reported, showing that migration could be caused.

PAHs can be found as impurities in plasticizers [27] and are often found in various polymers or some additives, e.g., carbon black. They have been found during the production and processing of polystyrene (PS) products [47]. In fact, low molecular weight PAHs were detected in PS materials that have been in contact with food, due to the formation of these PAHs during the production process and the sorption during their use. Li et al. [36] pointed out the influence of the use of a foaming agent in the increase in PAHs levels when comparing expanded PS and extruded PS. Other additives, such as auxochromes and chromophores, contribute to increased PAH concentrations in colored PS materials compared to colorless ones [36]. Table 1 summarizes the main findings related to the presence of PAH and POP in recyclates.

Table 1. Summary of important PAHs and POPs levels found in recycled items.

\begin{tabular}{|c|c|}
\hline Reference & Finding \\
\hline Vapenka et al. [46] & PAHs in more than $50 \%$ of packaging materials. $1212 \mathrm{mg} / \mathrm{kg}$ of fluorene \\
\hline Chen et al. [48] & $\begin{array}{c}\text { Styrofoam presents a greater ability to adsorb POPs, compared to PE and polypropylene (PP). Higher } \\
\text { PAH concentrations were found in plastic particles from coastal beaches }(1722.9-31764.8 \mu \mathrm{g} / \mathrm{kg}) \\
\text { rather than in plastic particles from open ocean areas (nd-6298.8 } \mu \mathrm{g} / \mathrm{kg})\end{array}$ \\
\hline Fisner et al. [41] & $\begin{array}{l}\text { Type (and color) of the polymers determine the concentration of PAHs. Increase in PAH } \\
\text { concentrations along a spectrum of darkening pellets }\end{array}$ \\
\hline Fisner et al. [49] & No correlation between the PAH content and the location of the plastic item \\
\hline Bouhroum et al. [43] & $\begin{array}{l}\text { Coastal debris contains high concentrations of PAHs and PCBs, while plastic debris found in remote } \\
\text { sites showed much lower concentrations. }\end{array}$ \\
\hline Budin et al. [44] & High levels of PBDD/Fs in plastic parts of some toys \\
\hline Pivnenko et al. [38] & Presence of BFRs associated with ABS and PS \\
\hline Rochman et al. [47] & HDPE, LDPE and PP sorb greater concentrations of PCBs and PAHs than PET and PVC \\
\hline Rani et al. [39] & $0.475 \mathrm{mg} / \mathrm{kg}$ of HBCD in expanded PS items \\
\hline Turner et al. [50-52] & Bromine in about $42 \%$ of WEEE samples, and $18 \%$ of non-WEEE \\
\hline Leslie et al. [53] & BFRs in plastic materials destined for recycling markets \\
\hline DiGangi et al. [45] & $1100 \mathrm{mg} / \mathrm{kg}$ PentaBDE and OctaBDE in recycled carpet padding \\
\hline
\end{tabular}

Chen et al. studied the marine microplastics bound dioxin-like chemicals [48]. They found that polymers such as styrofoam present a greater ability to adsorb POPs, compared to $\mathrm{PE}$ and polypropylene (PP). In addition, significantly higher PAH concentrations were found in plastic particles from coastal beaches $(1722.9-31764.8 \mu \mathrm{g} / \mathrm{kg}$ ) rather than in plastic particles from open ocean areas (nd-6298.8 $\mu \mathrm{g} / \mathrm{kg}$ ). In the same way, Fisner et al. [41] also showed that the type (and color) of the polymers determine the concentration of PAHs. These authors found that there is an increase in PAH concentrations along a spectrum of darkening pellets, and that $\mathrm{PE}$ and $\mathrm{PP}$ resins absorb significantly greater concentrations of PCBs and PAHs than polyethylene terephthalate (PET) and polyvinyl chloride (PVC). With respect to the location of the plastics, in opposition to Chen et al., Fisner et al. [49] show that 
there is not a correlation between the PAH content and the location of the plastic item, since PAH concentrations showed high variability, with no clear pattern. Bouhroum et al. [43] mention that coastal debris contains high concentrations of PAHs and PCBs, while plastic debris found in remote sites showed much lower concentrations. This may be due to the release of chemical substances or the degradation that occurs during transport by ocean currents and/or atmospheric air, to which the chemical and physical photo-transformation of plastic waste can be added. Teuten et al. [54] mention that PE accumulates more organic contaminants than other plastics, such as PP and PVC.

\subsection{Dioxin-Like POPS}

Budin et al. [44] studied the presence of brominated dioxins and furans (PBDD/Fs) in the plastic parts of some toys available on the market, determining high levels of PBDD/Fs and related TEQ levels, concluding that the sampled toys were most likely made with recycled plastics containing flame retardants. A recent study performed laboratory analysis of 95 Rubik's cubes and 16 additional samples from 26 countries in various regions, and found that $90 \%$ of the samples contained octabromodiphenyl ether (OctaBDE) in concentrations ranging from 1 to 1174 ppm [55].

PBDD/Fs have been recently detected in black plastic parts from toys $[44,56]$. Brominated congeners of dioxins and furans are known to have hazardous properties and are present as contaminants in commercial PBDEs (in low concentrations, but enough to be of concern) [27]. Furthermore, they can be formed in significantly greater amounts during low temperature thermal degradation $\left(<500^{\circ} \mathrm{C}\right)$ [21,57-59]. Under these conditions, many BFRs act as precursors to the formation of PBDFs through debromination and hydrogenation reactions, increasing the yield in the presence of $\mathrm{Sb}_{2} \mathrm{O}_{3}$. The evidence available indicates that PBDD/Fs, similar to their chlorinated analogues, are highly toxic [60] and more hazardous than the precursor POP-BDEs from which they were formed. Significantly, the United Nations Environment Program (UNEP) asserts that the formation of PBDD/Fs is the most important input to the health effects arising from the recycling of PBDEs [61].

Even though it has been shown that highly chlorinated congeners of different POPs have a great affinity for PE-like polymers [43], no evidence has been found thus far for the presence of PCDD/Fs or dioxin-like PCBs in recycled materials. If present, they would probably appear in significantly smaller amounts than PBDD/Fs, which are mainly formed from PBDEs via the precursor pathway [62]. However, metals such as $\mathrm{Ca}, \mathrm{Al}, \mathrm{Na}, \mathrm{Zn}$ and Fe and halogens such as $\mathrm{Cl}$ and $\mathrm{F}$, occurring in concentrations between 1 and 3000 ppm, have been recently detected in plastic packaging waste streams from different European sorting facilities [63]. If certain temperatures are reached during recycling operations, PCDD/Fs and/or PCBs could be formed via de novo synthesis, catalyzed by the presence of Fe or $\mathrm{Cu}$ [64] BFRs.

Much of the literature we found was about the presence of BFRs in plastic waste from contaminated areas. The dumping of electronic waste in landfills, with an appreciable amount of BFRs, has been related to the abnormal growth of the eggs of birds that live near landfills $[65,66]$. In this way, the contaminants in plastics can be transferred both to lower and higher tropic organisms [54].

Apart from illegal recycling, another reason for the presence of BFRs in recycled plastic samples is the lack of effective techniques that classify or eliminate the substances of interest and additives that have been incorporated into plastic matrices [67]. In particular, it is not possible today to achieve the complete removal or degradation of TBBPA during recycling.

Pivnenko et al. [38] studied the presence of BFRs in plastic solid wastes (PSW) and found that the highest concentrations were associated with acrylonitrile butadiene styrene (ABS) and polystyrene (PS), two materials that are commonly used in electronic equipment.

Rochman et al. [47] insist that high-density polyethylene (HDPE), LDPE and PP sorb greater concentrations of PCBs and PAHs than PET and PVC. This implies that PET and PVC pose a reduced risk of concentrating these hazardous chemicals onto the plastic debris ingested by animals. 
Rani et al. [39] measured the presence of hexabromocyclododecane (HBCD) in consumer products based on PS. They found levels as high as $0.475 \mathrm{mg} / \mathrm{kg}$ of HBCD in expanded PS items. Other BFRs were also detected in a majority of the expanded PS foam products, but in much lower concentrations.

Turner and others [50-52] detected bromine in about $42 \%$ of 267 samples of electrical and electronic items, and $18 \%$ of 789 analyses performed on non-electronic samples. The presence of bromine is linked to antimony, a component of flame retardant synergists such as $\mathrm{Sb}_{2} \mathrm{O}_{3}$, and lead, a heavy metal additive and contaminant [51]. The authors observed that most Br-contaminating items were black, suggesting that the recycling of electronic equipment, in particular that which is black in color, is deficient. For plastics of other colors, an association among $\mathrm{Br}$ and $\mathrm{Sb}$ or Pd is only observed in a few cases [50]. Turner [51] shows that black PSW presents technical and economic limitations imposed during the efficient separation of waste for recycling, which causes the BFRs to be dispersed in the environment and present in the least expected products. This highlights the illicit recycling of waste from electronic and electric equipment (WEEE) plastic into food contact items, and may be a reason as to why hazardous brominated flame retardants have been found in food contact materials on the EU market [26].

Some plastic that is part of WEEE is classified inefficiently and has the potential to introduce limited and dangerous substances into the recycled material, including BFRs, $\mathrm{Sb}$ and heavy metals $(\mathrm{Cd}, \mathrm{Cr}, \mathrm{Hg}$ and $\mathrm{Pb})[51,68]$. In this regard, some studies have explored the suitability of $\mathrm{X}$-ray fluorescence $(\mathrm{XRF})$ bromine measurements as a surrogate indicator of the presence of BFRs in polymers [50]. This would solve, at least in part, the problem that infrared detection supposes, as X-ray intensity is not affected by color [51]. It is an in-situ applicable technique that can give accurate and repeatable data at relatively low costs and with a minimal use of consumables [68].

Leslie et al. [53] pointed out the importance of the presence of BFRs in plastic materials destined for recycling markets. These POPs have been found in various plastic materials, including items used for the automotive and electronic industries [53], children's toys $[44,55,56]$ and personal care products [69].

DiGangi et al. [45] studied more than 40 samples of recycled carpet padding, looking for the concentration of different BFRs in the materials. They found that the highest levels measured in the samples were for pentabromodiphenyl ether (PentaBDE) followed by OctaBDE and decabromodiphenyl (DecaBDE). The highest level of PentaBDE found was around $1100 \mathrm{mg} / \mathrm{kg}$, and that was interfered in the recycling process of the materials.

\section{Migration from PSW to Other Materials}

The diffusion of different species from plastics to several media has been considered. Sun et al. [70] showed that the release kinetics of BFRs could be modeled as one-dimensional diffusion. The diffusion coefficients of polybrominated diphenyl ethers (PBDEs) and 1,2bis (2,4,6-tribromophenoxy)ethane (BTBPE) (at $\left.30^{\circ} \mathrm{C}\right)$ in the plastic matrices (the plastic exteriors of two scrap computer displays, made of ABS) were estimated to be in the range of $10^{-27.16}$ to $10^{-19.96} \mathrm{~m}^{2} / \mathrm{s}$. For microplastics, also made of ABS, Sun et al. [71] determined that the coefficients for BFRs ranged from $10^{-28.30}$ to $10^{-20.84} \mathrm{~m}^{2} / \mathrm{s}$, with the values decreasing with their molecular diameters. Ionas et al. [56] pointed out the high level of danger posed by the presence of PBDEs in mouthing toys for small children. The authors conclude that BDE-209 is the most present and that the amount leached out when in contact with saliva for only $15 \mathrm{~min}$ is much higher than that observed for certified materials in $16 \mathrm{~h}$.

Rusina et al. [72] estimated the values of diffusion coefficients for PCBs and PAHs in LDPE and polydimethylsiloxane (PDMS or silicone rubber), finding values 2-2.5 orders of magnitude lower in LDPE than in PDMS polymers. Specifically, for PAH molecules, the diffusion coefficient was lower than for PCBs with a similar molecular weight, probably because of their more rigid structure. Valderrama et al. [73] contrarily found higher coefficients in silicone rubber than in LDPE, when evaluating the properties of PBDEs. 
Li et al. [36] measured the diffusion coefficients of eight detected PAHs in PS food contact materials, showing that short times and low temperatures minimize the migration of these compounds from plastics to the surrounding media. Teuten et al. [54] showed the transport and release of chemicals from plastics to the environment and mentioned that PCBs could transfer from contaminated plastics to streaked shearwater chicks. The measured values of diffusion coefficients for toluene, o-xylene and tetrachloroethylene were reported.

The migration of POPs such as bisphenol A has been observed from can coatings into foodstuffs [74]. Recently, Franz et al. [75] determined the concentrations of post-consumer substances in PET containers used for a range of non-food product applications taken from the market. The authors suspect that PET containers are recycled into products that will be in contact with food, but finally concluded that if the non-food PET fraction is below 5\% it does not present any risk or problem for the consumer.

The break-down products from constituents of food contact materials present a lower molecular weight than their parent compounds, which improves their capacity for diffusion, thus exhibiting a greater ability to migrate from plastic materials to food [76].

Complete information on all of the chemicals involved is needed for a complete characterization of the hazards of chemicals potentially released during the manufacture, use, disposal and/or recycling of packaging. Groh et al. [24] compiled all of this information and presented it to the Chemical Substances Associated with Plastic Packaging (CPPdb) database, which includes most of the chemical substances used during manufacture and/or present in articles of final packing.

\section{Further Research Work}

As has been shown, one of the most important limitations of plastic recycling is the quality of the recycled product. Most recycled materials are intended for 'downcycling', meaning that the product obtained is used in applications of lower quality than the original ones. For example, virgin high density polyethylene (HDPE) is commonly used for the manufacture of shower gel bottles; however, the destiny of recycled HDPE is usually related to gardening devices, such as pots for plants, or for paint packaging. Thus, currently only a few products with low added value can use recycled plastic, producing a quick saturation of the market and a real impossibility of recycling all of the plastic waste generated. In this way, if the market demand for recycled plastic does not increase enough, the paradox that the recycled plastic has to be disposed of in landfills or incinerated could occur.

The majority of recycled plastics have a grey color, low mechanical properties, bad smell and can present substances that are hazardous to health, which restricts their use in the polymers sector. In order to overcome this situation, the quality of recycled products should be improved, acting in the 'upstream' section, by enhancing the raw material to be recycled. For example, in the case of post-consumer packaging, the implementation of a return deposit system would reduce the cross-contamination in the plastic and the heterogeneity of materials. As well as this, the quality of a polymer can be upgraded through the recycling process steps by improving the performance of sorting, washing, drying and extrusion, or in the 'downstream' section by refining the final recycled plastic. The latter option refers to the treatment of the final pellets; for example, some studies applied supercritical $\mathrm{CO}_{2}$ for the extraction of residual organic contamination in recycled pellets. This is an environmentally friendly solution as no hazardous solvents are used, but it demands high investment and operating costs as the working pressure is above 70 bars. For this reason, although the results were successful, this technology has not been implemented at an industrial scale yet. Therefore, the recycling industry is looking forward to a solution that is not only technically, but also economically, feasible.

Additionally, the lack of traceability of the starting material is another limitation in terms of the quality of the recycled plastic when using it in higher-value applications ('upcycling'). The post-consumer material may contain additives that were useful in the original application, but that may be an issue for the future applications of the correspond- 
ing recyclate (Intentionally Added Substances or IAS). Thus, for example, some of the additives that were very common a few years ago and are now much more limited may appear again in recycled plastic. This could be the case of Bisphenol A, nonylphenols and plasticizing phthalates. On the other hand, during the previous use, the plastic could have come into contact with undesired substances, such as food leftovers or rests of detergents, generating bad odors, or dangerous substances, as could be the case of pesticides.

Accordingly, in order to improve the applications of upcycling plastics, the following two types of actions are necessary: (a) to develop methods to identify possible IASs and NIASs in recycled plastics and (b) to develop technologies to reduce the amount of these compounds in recycled plastics through 'upgrading'. In this way, different aspects associated with mechanical recycling, aiming at the improvement of this incipient industrial process, should be addressed as follows:

(1) Identification of IASs /NIASs: It is necessary to deepen the study of microcontaminants (heavy metals, pesticides, polyaromatic hydrocarbons (PAHs), polychlorinated biphenyls (PCBs) and polychlorinated dioxins and furans (PCDD/Fs)), which have chemical structures very similar to those of IASs/NIASs, with an objective to identify the compounds present in recycled plastics that may negatively affect their application.

(2) Removal of NIASs: In a way, recycled plastic can be considered a contaminated material, such as soil or water. Many of the techniques that are used for removing pollutants could also be used for IAS/NIAS elimination. The techniques used for odor elimination and contaminants' reduction should be further explored, such as the extraction of organic substances by using environmentally friendly solvents, treatments with hot water, hot air, UV lamps and heavy solvents, among others.

(3) Life Cycle Analysis (LCA): For the selection of sustainable solutions, it is necessary to make a life cycle analysis to prevent the proposed solution from having a higher environmental impact than the current situation.

\section{Conclusions}

In this review article, the presence of contaminants in residual plastics and in products from recycled plastics (recyclates) has been summarized.

The extraction methods used by the researchers have been reviewed, with special emphasis on the use of the solubility parameter to study the compatibility of different polymer-solvent pairs.

Important differences have been found in the contents of PAHs and POPs in different plastics.

Literature shows that hazardous substances are potentially present in plastic waste, but a limited number of publications on measured pollutant concentrations in plastic waste fractions exist, let alone in recycled polymers. Therefore, improved data compilation and analyses are necessary to identify relevant substances of concern and their concentrations in secondary resources.

It is important to note that the presence of these pollutants can be very dangerous for the subsequent use of consumer products, and, therefore, recycling techniques are required to eliminate contamination and to increase both the percentage of recycled plastics and their quality.

Author Contributions: Conceptualization, J.M., S.S.N., N.O. and J.A.C.; writing-original draft preparation, J.A.C. and N.O.; writing - review and editing, J.M., S.S.N. and N.O.; supervision, J.M. and N.O.; funding acquisition, J.A.C. All authors have read and agreed to the published version of the manuscript.

Funding: This research was funded by Ministry of Science and Innovation (Spain), grant number PID2019-105359RB-I00.

Institutional Review Board Statement: Not applicable.

Informed Consent Statement: Not applicable. 
Acknowledgments: This work was supported by the Ministry of Science and Innovation (Spain) [grant number PID2019-105359RB-I00]. The research received funds for covering the costs to publish in open access.

Conflicts of Interest: The authors declare no conflict of interest.

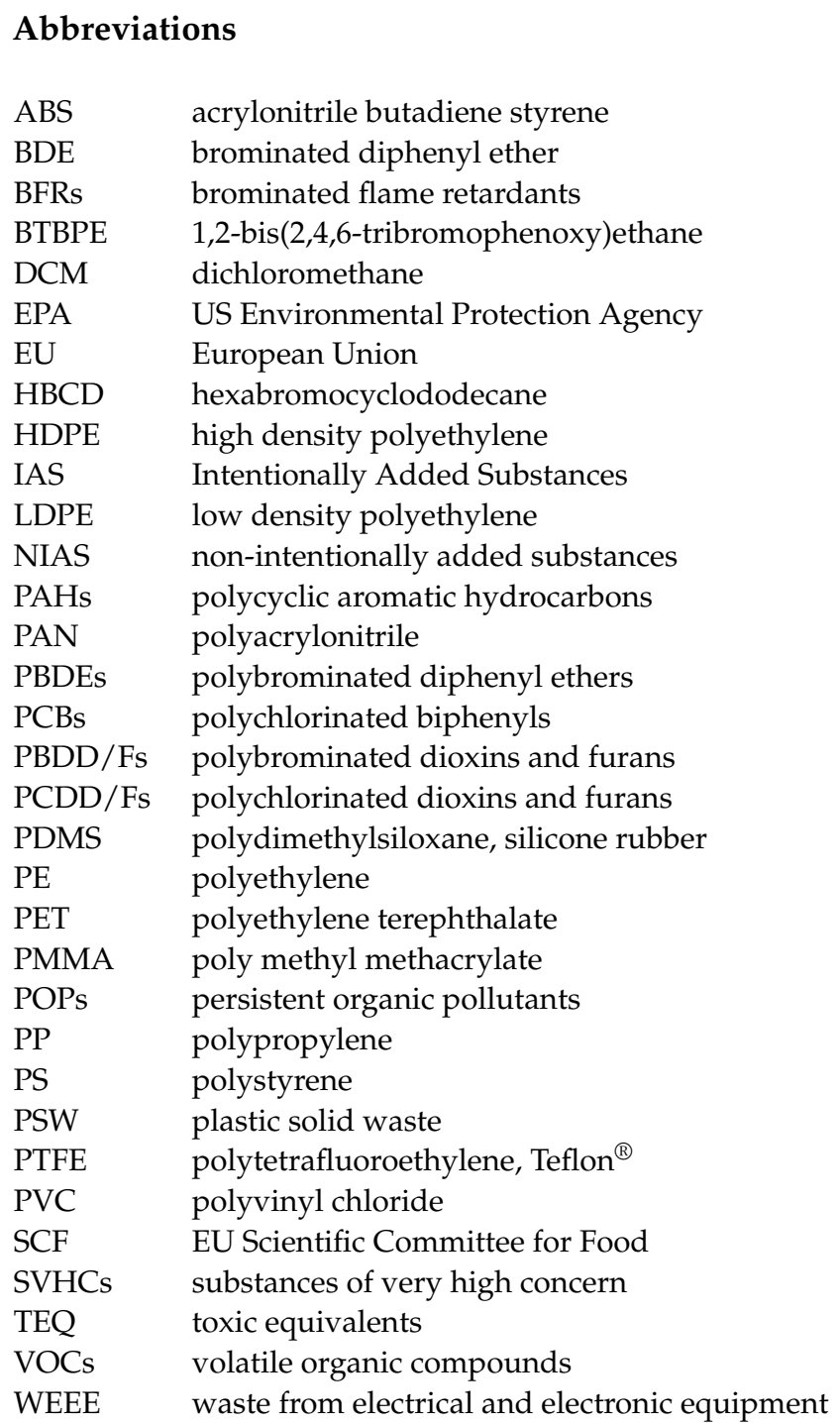

\section{References}

1. Andrady, A.L.; Neal, M.A. Applications and societal benefits of plastics. Philos. Trans. R. Soc. B Biol. Sci. 2009, 364, 1977-1984. [CrossRef] [PubMed]

2. Association of Plastic Manufacturers. Plastics—the Facts 2020; PlasticEurope: London, UK, 2020; Volume 16.

3. Miller, S.; Bolger, M.; Copello, L. Reusable Solutions: How Governments Can Help Stop Single-Use Plastic Pollution; Zero Waste Europe: Brussels, Belgium, 2009.

4. European Commission. EuRIC-Plastic Recycling Factsheet/European Circular Economy Stakeholder Platform. Available online: https:/ / circulareconomy.europa.eu/platform/en/knowledge/euric-plastic-recycling-factsheet (accessed on 26 May 2021 ).

5. European Commission. Communication from the Commission to the European Parliament, the Council, the European Economic and Social Committee and the Committee of the Regions Closing the Loop-An EU Action Plan for the Circular Economy; European Commission: Brussels, Belgium, 2015.

6. European Commission. Communication from the Commission to the European Parliament, the Council, the European Economic and Social Committee and the Committee of the Regions-A European Strategy for Plastics in a Circular Economy; European Commission: Brussels, Belgium, 2018.

7. European Comission. Changing the Way We Use Plastics; European Commission: Brussels, Belgium, 2018 ; Volume 4.

8. European Parliament. Directive (EU) 2018/852 of the European Parliament and of the Council of 30 May 2018 amending Directive 94/62/EC on packaging and packaging waste. Off. J. Eur. Union 2018, 2018, 141-154. 
9. American Society for Testing Materials. ASTM D7209-06: Standard Guide for Waste Reduction, Resource Recovery, and Use of Recycled Polymeric Materials and Products; American Society for Testing and Materials: West Conshohocken, PA, USA, 2013 ; pp. 1-7.

10. International Organization for Standarization-ISO. ISO 15270_2008 (en), Plastics_Guidelines for the Recovery and Recycling of Plastics Waste. Available online: https:/ / www.iso.org/standard/45089.html (accessed on 3 May 2021).

11. Hopewell, J.; Dvorak, R.; Kosior, E. Plastics recycling: Challenges and opportunities. Philos. Trans. R. Soc. B Biol. Sci. 2009, 364, 2115-2126. [CrossRef] [PubMed]

12. Achilias, D.; Roupakias, C.; Megalokonomos, P.; Lappas, A.; Antonakou, E. Chemical recycling of plastic wastes made from polyethylene (LDPE and HDPE) and polypropylene (PP). J. Hazard. Mater. 2007, 149, 536-542. [CrossRef]

13. Karmakar, G.P. Regeneration and Recovery of Plastics. Ref. Modul. Mater. Sci. Mater. Eng. 2020. [CrossRef]

14. Vollmer, I.; Jenks, M.J.F.; Roelands, M.C.P.; White, R.J.; Van Harmelen, T.; De Wild, P.; Van Der Laan, G.P.; Meirer, F.; Keurentjes, J.T.F.; Weckhuysen, B.M. Beyond Mechanical Recycling: Giving New Life to Plastic Waste. Angew. Chem. Int. Ed. 2020, 59, 15402-15423. [CrossRef] [PubMed]

15. Wagner, S.; Schlummer, M. Legacy additives in a circular economy of plastics: Current dilemma, policy analysis, and emerging countermeasures. Resour. Conserv. Recycl. 2020, 158, 104800. [CrossRef]

16. Gullett, B.K.; Wyrzykowska, B.; Grandesso, E.; Touati, A.; Tabor, D.G.; Ochoa, G.S. PCDD/F, PBDD/F, and PBDE Emissions from Open Burning of a Residential Waste Dump. Environ. Sci. Technol. 2010, 44, 394-399. [CrossRef]

17. Gullett, B.; Sarofim, A.; Smith, K.; Procaccini, C. The Role of Chlorine in Dioxin Formation. Process. Saf. Environ. Prot. 2000, 78, 47-52. [CrossRef]

18. Conesa, J.A.; Fullana, A.; Font, R. De Novo Synthesis of PCDD/F by Thermogravimetry. Environ. Sci. Technol. 2002, 36, 263-269. [CrossRef]

19. Ortuño, N.; Conesa, J.A.; Moltó, J.; Font, R. De Novo Synthesis of Brominated Dioxins and Furans. Environ. Sci. Technol. 2014, 48, 7959-7965. [CrossRef]

20. Ortuño, N.; Moltó, J.; Conesa, J.A.; Font, R. Formation of brominated pollutants during the pyrolysis and combustion of tetrabromobisphenol A at different temperatures. Environ. Pollut. 2014, 191, 31-37. [CrossRef] [PubMed]

21. Ebert, J. Formation of PBDD/F from flame-retarded plastic materials under thermal stress. Environ. Int. 2003, 29, 711-716. [CrossRef]

22. USEPA Waste Reduction Model (WARM). Available online: https:/ / www.epa.gov/warm (accessed on 11 May 2021).

23. Singh, N.; Hui, D.; Singh, R.; Ahuja, I.; Feo, L.; Fraternali, F. Recycling of plastic solid waste: A state of art review and future applications. Compos. Part B Eng. 2017, 115, 409-422. [CrossRef]

24. Groh, K.J.; Backhaus, T.; Carney-Almroth, B.; Geueke, B.; Inostroza, P.; Lennquist, A.; Leslie, H.A.; Maffini, M.; Slunge, D.; Trasande, L.; et al. Overview of known plastic packaging-associated chemicals and their hazards. Sci. Total. Environ. 2019, 651, 3253-3268. [CrossRef] [PubMed]

25. Horodytska, O.; Cabanes, A.; Fullana, A. Non-intentionally added substances (NIAS) in recycled plastics. Chemosphere 2020, 251, 126373. [CrossRef] [PubMed]

26. European Commission. A Circular Economy for Plastics-Insights from Research and Innovation to Inform Policy and Funding Decisions; European Commission: Brussels, Belgium, 2019.

27. Stenmarck, Å.; Belleza, E.L.; Fråne, A.; Busch, N.; Larsen, Å.; Wahlström, M. Hazardous Substances in Plastics-Ways to Increase Recycling —Ways to Increase Recycling; Nordic Council of Ministers: Copenhagen, Denmark, 2017; ISBN 9789188319517.

28. Cabanes, A.; Valdés, F.; Fullana, A. A review on VOCs from recycled plastics. Sustain. Mater. Technol. 2020, 25, e00179. [CrossRef]

29. Lerda, D. Polycyclic Aromatic Hydrocarbons (PAHs) Factsheet, 4th ed; JRC Technical Notes: Geel, Belgium, 2011.

30. Stockholm Convention Home Page. Available online: http://chm.pops.int/Home/tabid/2121/Default.aspx (accessed on 10 May 2021).

31. Singla, M.; Díaz, J.; Broto-Puig, F.; Borrós, S. Sorption and release process of polybrominated diphenyl ethers (PBDEs) from different composition microplastics in aqueous medium: Solubility parameter approach. Environ. Pollut. 2020, $262,114377$. [CrossRef] [PubMed]

32. Sánchez-Camargo, A.D.P.; Bueno, M.; Parada-Alfonso, F.; Cifuentes, A.; Ibáñez, E. Hansen solubility parameters for selection of green extraction solvents. TrAC Trends Anal. Chem. 2019, 118, 227-237. [CrossRef]

33. Lu, Y.; Shi, J.-J.; Sun, L. Investigation of the selection of extraction solvent for extracting the n-alkane from diesel by means of solubility parameters theory. J. Fuel Chem. Technol. 2008, 36, 297-301. [CrossRef]

34. Polymer Database Polymer Solubility. 2015. Available online: https://polymerdatabase.com/polymer\%20physics/Polymer\%20 Solubility.html (accessed on 10 June 2021).

35. He, N.; Smeds, A.; Friman, R.; Rosenholm, J.B. Solubility parameters of biopolymers. Phys. Chem. Liq. 2013, 51, 302-316. [CrossRef]

36. Li, S.-Q.; Ni, H.-G.; Zeng, H. PAHs in polystyrene food contact materials: An unintended consequence. Sci. Total. Environ. 2017, 609, 1126-1131. [CrossRef] [PubMed]

37. Nerín, C.; Tornés, A.R.; Domeño, C.; Cacho, J. Absorption of Pesticides on Plastic Films Used as Agricultural Soil Covers. J. Agric. Food Chem. 1996, 44, 4009-4014. [CrossRef]

38. Pivnenko, K.; Granby, K.; Eriksson, E.; Astrup, T. Recycling of plastic waste: Screening for brominated flame retardants (BFRs). Waste Manag. 2017, 69, 101-109. [CrossRef] 
39. Rani, M.; Shim, W.J.; Han, G.M.; Jang, M.; Song, Y.K.; Hong, S.H. Hexabromocyclododecane in polystyrene based consumer products: An evidence of unregulated use. Chemosphere 2014, 110, 111-119. [CrossRef]

40. León, V.M.; García-Agüera, I.; Moltó, V.; Fernández-González, V.; Llorca-Pérez, L.; Andrade, J.M.; Muniategui, S.; Campillo, J.A. PAHs, pesticides, personal care products and plastic additives in plastic debris from Spanish Mediterranean beaches. Sci. Total Environ. 2019, 670, 672-684. [CrossRef]

41. Fisner, M.; Majer, A.; Taniguchi, S.; Bícego, M.; Turra, A.; Gorman, D. Colour spectrum and resin-type determine the concentration and composition of Polycyclic Aromatic Hydrocarbons (PAHs) in plastic pellets. Mar. Pollut. Bull. 2017, 122, 323-330. [CrossRef]

42. Iñiguez, M.E.; Conesa, J.A.; Fullana, A. Pollutant content in marine debris and characterization by thermal decomposition. Mar. Pollut. Bull. 2017, 117, 359-365. [CrossRef] [PubMed]

43. Bouhroum, R.; Boulkamh, A.; Asia, L.; Lebarillier, S.; Ter Halle, A.; Syakti, A.; Doumenq, P.; Malleret, L.; Wong-Wah-Chung, P. Concentrations and fingerprints of PAHs and PCBs adsorbed onto marine plastic debris from the Indonesian Cilacap coast and theNorth Atlantic gyre. Reg. Stud. Mar. Sci. 2019, 29, 100611. [CrossRef]

44. Budin, C.; Petrlik, J.; Strakova, J.; Hamm, S.; Beeler, B.; Behnisch, P.; Besselink, H.; van der Burg, B.; Brouwer, A. Detection of high PBDD/Fs levels and dioxin-like activity in toys using a combination of GC-HRMS, rat-based and human-based DR CALUX®reporter gene assays. Chemosphere 2020, 251, 126579. [CrossRef]

45. DiGangi, J.; Strakova, J. A survey of PBDEs in recycled carpet padding. Organohalogen Compd. 2011, 73, 2067-2070.

46. Vápenka, L.; Vavrouš, A.; Votavová, L.; Kejlová, K.; Dobiáš, J.; Sosnovcová, J. Contaminants in the paper-based food packaging materials used in the Czech Republic. J. Food Nutr. Res. 2016, 55, 361-373.

47. Rochman, C.M.; Hoh, E.; Hentschel, B.T.; Kaye, S. Long-Term Field Measurement of Sorption of Organic Contaminants to Five Types of Plastic Pellets: Implications for Plastic Marine Debris. Environ. Sci. Technol. 2013, 47, 1646-1654. [CrossRef]

48. Chen, Q.; Zhang, H.; Allgeier, A.; Zhou, Q.; Ouellet, J.D.; Crawford, S.; Luo, Y.; Yang, Y.; Shi, H.; Hollert, H. Marine microplastics bound dioxin-like chemicals: Model explanation and risk assessment. J. Hazard. Mater. 2019, 364, 82-90. [CrossRef]

49. Fisner, M.; Taniguchi, S.; Majer, A.P.; Bícego, M.C.; Turra, A. Concentration and composition of polycyclic aromatic hydrocarbons (PAHs) in plastic pellets: Implications for small-scale diagnostic and environmental monitoring. Mar. Pollut. Bull. 2013, 76, 349-354. [CrossRef]

50. Shaw, E.J.; Turner, A. Recycled electronic plastic and marine litter. Sci. Total Environ. 2019, 694, 133644. [CrossRef]

51. Turner, A. Black plastics: Linear and circular economies, hazardous additives and marine pollution. Environ. Int. 2018, 117, 308-318. [CrossRef]

52. Turner, A.; Filella, M. Bromine in plastic consumer products-Evidence for the widespread recycling of electronic waste. Sci. Total Environ. 2017, 601-602, 374-379. [CrossRef] [PubMed]

53. Leslie, H.; Leonards, P.; Brandsma, S.; de Boer, J.; Jonkers, N. Propelling plastics into the circular economy-weeding out the toxics first. Environ. Int. 2016, 94, 230-234. [CrossRef] [PubMed]

54. Teuten, E.L.; Saquing, J.M.; Knappe, D.R.U.; Barlaz, M.A.; Jonsson, S.; Björn, A.; Rowland, S.J.; Thompson, R.C.; Galloway, T.S.; Yamashita, R.; et al. Transport and release of chemicals from plastics to the environment and to wildlife. Philos. Trans. R. Soc. $B$ Biol. Sci. 2009, 364, 2027-2045. [CrossRef] [PubMed]

55. DiGangi, J.; Strakova, J.; Bell, L. POPs Recycling Contaminates Children's Toys with Toxic Flame Retardants. 2017. Available online: https://ipen.org/sites/default/files/documents / toxic_toy_report_2017_update_v2_1-en.pdf (accessed on 10 June 2021).

56. Ionas, A.C.; Ulevicus, J.; Ballesteros-Gómez, A.; Brandsma, S.H.; Leonards, P.E.; van de Bor, M.; Covaci, A. Children's exposure to polybrominated diphenyl ethers (PBDEs) through mouthing toys. Environ. Int. 2016, 87, 101-107. [CrossRef] [PubMed]

57. Wang, L.-C.; Hsi, H.-C.; Wang, Y.-F.; Lin, S.-L.; Chang-Chien, G.-P. Distribution of polybrominated diphenyl ethers (PBDEs) and polybrominated dibenzo-p-dioxins and dibenzofurans (PBDD/Fs) in municipal solid waste incinerators. Environ. Pollut. 2010, 158, 1595-1602. [CrossRef] [PubMed]

58. Ortuño, N.; Lundstedt, S.; Lundin, L. Emissions of PBDD/Fs, PCDD/Fs and PBDEs from flame-retarded high-impact polystyrene under thermal stress. Chemosphere 2015, 123, 64-70. [CrossRef] [PubMed]

59. Zhan, F.; Zhang, H.; Cao, R.; Fan, Y.; Xu, P.; Chen, J. Release and Transformation of BTBPE During the Thermal Treatment of Flame Retardant ABS Plastics. Environ. Sci. Technol. 2018, 53, 185-193. [CrossRef]

60. Berg, M.V.D.; Denison, M.S.; Birnbaum, L.S.; DeVito, M.J.; Fiedler, H.; Falandysz, J.; Rose, M.; Schrenk, D.; Safe, S.; Tohyama, C.; et al. Polybrominated Dibenzo-p-Dioxins, Dibenzofurans, and Biphenyls: Inclusion in the Toxicity Equivalency Factor Concept for Dioxin-Like Compounds. Toxicol. Sci. 2013, 133, 197-208. [CrossRef]

61. UNEP. Supporting Document for the Draft Technical Paper Developed in Accordance with the Work Programmes on New Persistent Organic Pollutants as Adopted by the Conference of the Parties; UNEP: Nairobi, Kenya, 2010.

62. Weber, R.; Kuch, B. Relevance of BFRs and thermal conditions on the formation pathways of brominated and brominatedchlorinated dibenzodioxins and dibenzofurans. Environ. Int. 2003, 29, 699-710. [CrossRef]

63. Roosen, M.; Mys, N.; Kusenberg, M.; Billen, P.; Dumoulin, A.; Dewulf, J.; Van Geem, K.M.; Ragaert, K.; De Meester, S. Detailed Analysis of the Composition of Selected Plastic Packaging Waste Products and Its Implications for Mechanical and Thermochemical Recycling. Environ. Sci. Technol. 2020, 54, 13282-13293. [CrossRef]

64. Fujimori, T.; Takaoka, M.; Takeda, N. Influence of $\mathrm{Cu}, \mathrm{Fe}, \mathrm{Pb}$, and $\mathrm{Zn}$ Chlorides and Oxides on Formation of Chlorinated Aromatic Compounds in MSWI Fly Ash. Environ. Sci. Technol. 2009, 43, 8053-8059. [CrossRef] 
65. Tongue, A.D.; Reynolds, S.J.; Fernie, K.J.; Harrad, S. Flame retardant concentrations and profiles in wild birds associated with landfill: A critical review. Environ. Pollut. 2019, 248, 646-658. [CrossRef]

66. Gilbert, N.I.; Correia, R.A.; Silva, J.P.; Pacheco, C.; Catry, I.; Atkinson, P.W.; Gill, J.A.; Franco, A.M.A. Are white storks addicted to junk food? Impacts of landfill use on the movement and behaviour of resident white storks (Ciconia ciconia) from a partially migratory population. Mov. Ecol. 2016, 4,1-13. [CrossRef]

67. Hahladakis, J.N.; Velis, C.A.; Weber, R.; Iacovidou, E.; Purnell, P. An overview of chemical additives present in plastics: Migration, release, fate and environmental impact during their use, disposal and recycling. J. Hazard. Mater. 2018, 344, 179-199. [CrossRef]

68. Guzzonato, A.; Puype, F.; Harrad, S. Improving the accuracy of hand-held X-ray fluorescence spectrometers as a tool for monitoring brominated flame retardants in waste polymers. Chemosphere 2016, 159, 89-95. [CrossRef]

69. Cabanes, A.; Fullana, A. New methods to remove volatile organic compounds from post-consumer plastic waste. Sci. Total Environ. 2021, 758, 144066. [CrossRef]

70. Sun, B.; Hu, Y.; Cheng, H.; Tao, S. Kinetics of Brominated Flame Retardant (BFR) Releases from Granules of Waste Plastics. Environ. Sci. Technol. 2016, 50, 13419-13427. [CrossRef]

71. Sun, B.; Hu, Y.; Cheng, H.; Tao, S. Releases of brominated flame retardants (BFRs) from microplastics in aqueous medium: Kinetics and molecular-size dependence of diffusion. Water Res. 2019, 151, 215-225. [CrossRef] [PubMed]

72. Rusina, T.; Smedes, F.; Klanova, J. Diffusion coefficients of polychlorinated biphenyls and polycyclic aromatic hydrocarbons in polydimethylsiloxane and low-density polyethylene polymers. J. Appl. Polym. Sci. 2010, 116, 1803-1810. [CrossRef]

73. Valderrama, J.F.N.; Baek, K.; Molina, F.J.; Allan, I.J. Implications of observed PBDE diffusion coefficients in low density polyethylene and silicone rubber. Environ. Sci. Process. Impacts 2015, 18, 87-94. [CrossRef] [PubMed]

74. Zou, Y.; Lin, S.; Chen, S.; Zhang, H. Determination of bisphenol A diglycidyl ether, novolac glycidyl ether and their derivatives migrated from can coatings into foodstuff by UPLC-MS/MS. Eur. Food Res. Technol. 2012, 235, 231-244. [CrossRef]

75. Franz, R.; Welle, F. Contamination Levels in Recollected PET Bottles from Non-Food Applications and their Impact on the Safety of Recycled PET for Food Contact. Molecules 2020, 25, 4998. [CrossRef] [PubMed]

76. Geueke, B. Dossier Non-intentionally added substances (NIAS). Food Packag. Forum 2018, 7. [CrossRef] 